\title{
Pengaruh compulsive gaming terhadap learning outcome siswa SMPN 1 Porong
}

\author{
Mokhammad Ilham Fuady, Siti Malikhah Tawaf, I Dewa Putu Eskasasnanda*, I Nyoman \\ Ruja \\ Universitas Negeri Malang, Jl. Semarang No. 5 Malang, Jawa Timur, Indonesia \\ *Penulis korespondensi, Surel: dewa.putu.eskasasnanda.fis@um.ac.id
}

Paper received: 02-03-2021; revised: 15-03-2021; accepted: 30-03-2021

\begin{abstract}
This study aims to describe (1) the background of SMPN 1 Porong students playing clash of clans games, (2) the characteristics of clash of clans game players at SMPN 1 Porong, (3) the impact of clash of clans game on students' learning outcomes at SMPN 1 Porong. The research was conducted at SMPN 1 Porong Subdistrict Porong Sidoarjo which was designed using qualitative approach with descriptive research type. The results of this study are: (1) students playing clash of clans games due to the influence of friends, loneliness and supportive facilities; (2) The characteristics of clash of clans players at SMPN 1 Porong are male, have free time, players are economically well-off students; (3) The influence of clash of clans game addiction on the learning outcomes of SMPN 1 Porong students is that students become easily lost concentration so that their learning outcomes are less satisfactory, with average learning outcomes (80) and slightly above average (82).
\end{abstract}

Keywords: games; clash of clans; students; learning outcomes

\begin{abstract}
Abstrak
Penelitian ini bertujuan untuk mendeskripsikan (1) latar belakang siswa SMPN 1 Porong bermain game clash of clans, (2) karakteristik pemain game clash of clans di SMPN 1 Porong, (3) dampak game clash of clans terhadap hasil belajar siswa di SMPN 1 Porong. Penelitian dilakukan di SMPN 1 Porong Kecamatan Porong Kabupaten Sidoarjo yang dirancang menggunakan pendekatan kualitatif dengan jenis penelitian deskriptif. Hasil penelitian ini adalah: (1) siswa bermain game clash of clans dikarenakan pengaruh teman, kesepian dan fasilitas yang mendukung; (2) Karakteristik pemain game clash of clans di SMPN 1 Porong adalah laki-laki, memiliki waktu luang, pemain merupakan siswa yang berkecukupan dalam segi ekonomi; (3) pengaruh kecanduan game clash of clans terhadap hasil belajar siswa SMPN 1 Porong adalah siswa menjadi mudah hilang konsentrasi sehingga hasil belajar mereka kurang memuaskan, dengan hasil belajar rata-rata (80) dan sedikit di atas rata-rata (82).
\end{abstract}

Kata kunci: game; clash of clans; siswa; hasil belajar

\section{Pendahuluan}

Manusia sebagai makhluk yang diciptakan Tuhan pasti memiliki kebutuhan. Kebutuhan manusia ada bermacam-macam, salah satunya adalah kebutuhan memperoleh hiburan. Hiburan merupakan suatu bentuk kegiatan guna menghilangkan rasa sedih, stres, bosan atau segala sesuatu yang berhubungan dengan suasana sedih manusia. Berbagai macam hiburan bagi manusia setiap tahun selalu berkembang seiring dengan perkembangan teknologi, salah satu bentuk hiburan yang berkembang beberapa tahun ini adalah game online. Game online pada beberapa tahun terakhir sudah bisa dimaikan melalui smartphone.

Game online melalui smartphone ini lebih disenangi anak-anak karena lebih mobile dan dapat dimainkan lebih fleksibel. Perkembangan teknologi memunculkan berbagai jenis game berbasis smartphone salah satunya adalah game Clash of Clans. Partisipasi remaja dalam 
memainkan game online begitu besar sehingga mereka menjadi kecanduan dan melupakan tugas utama sebagai seorang pelajar. Fitur dari dalam game online secara tidak langsung telah membawa dampak bagi pemain untuk terus-menerus bermain. Fitur chat juga memanjakan pemain dalam berinteraksi dengan sesama pemain dengan mudah.

Clash of clans merupakan game online bertema Massively Multiplayer Online Real-Time Strategy (MMORTS). Game ini memiliki ciri khas di mana pemain harus mengatur strategi permainan. Game clash of clans memiliki sifat yang mengikat waktu bagi pemainnya sehingga pemain akan sering kali melihat atau membuka game ini. Dampak dari kecanduan game clash of clans dinilai berbahaya bagi pelajar terutama siswa SMPN 1 Porong. Ketika pelajar menjadi kecanduan game online dan tidak dapat lepas dari smartphone, mereka akan menjadi anti sosial, selain itu sulitnya konsentrasi untuk belajar dikarenakan memikirkan game saja. Dampak dari hilangnya konsentrasi belajar adalah hasil belajar mereka menjadi turun.

\section{Metode}

Penelitian ini menggunakan pendekatan kualitatif dengan jenis penelitian deskriptif. Peran peneliti di lapangan yaitu sebagai instrumen kunci yang tidak boleh digantikan oleh orang lain. SMPN 1 Porong dipilih berdasarkan bahwa SMPN ini merupakan salah satu sekolah yang tidak melarang siswa membawa smartphone ke sekolah. Adanya free wifi di sekolah tersebut yang juga memudahkan siswa dalam bermain game online clash of clans di sekolah. Guru BK merupakan informan pendukung, sedangkan siswa dan guru wali kelas adalah informan kunci. Teknik pengumpulan data menggunakan observasi, wawancara mendalam, dan dokumentasi. Teknik analisis data yang digunakan adalah model interaktif (Miles, M. B. \& Huberman, A. M, 1992) yang terdiri dari pengumpulan data, reduksi data, penyajian data, dan penarikan kesimpulan. Pengecekan keabsahan data dilakukan dengan teknik triangulasi baik triangulasi sumber, waktu, maupun teknik.

\section{Hasil dan Pembahasan}

\subsection{Latar Belakang Siswa SMPN 1 Porong Bermain Game Clash of Clans}

Remaja merupakan periode bertumbuhnya seseorang dalam masa transisi dari masa kanak-kanak ke masa dewasa (Mappiare, 1982) Siswa dikatakan berada pada masa remaja yakni ketika menempuh jenjang pendidikan menengah pertama hingga menengah atas sesuai dengan usia perkembangannya. Pada masa ini ketertarikan serta ikatan terhadap teman sebaya menjadi sangat kuat. Keadaan seperti ini menjadikan remaja kelompok tersendiri karena memiliki anggapan bahwa hanya sesama remaja yang dapat saling memahami. Siswa SMP mulai belajar memahami orang lain dan cenderung mendekatkan diri dengan remaja lain yang secara psikologis memiliki kesamaan dalam minat atau hobi (Farida, 2014). Salah satu kesamaan minat dan hobi remaja adalah bermain game online.

Berdasarkan hasil penelitian, dapat diketahui bahwa siswa SMPN 1 Porong bermain game clash of clans dikarenakan faktor teman sebaya. Siswa SMPN 1 Porong bermain game clash of clans karena teman mereka memainkannya juga. Kedekatan remaja dengan teman sebayanya tidak dapat dihindarkan salah satunya bermain game clash of clans. Mereka merasa tertarik mencoba agar dapat bermain bersama-sama dan berkumpul dengan teman mereka. 
Siswa SMPN 1 Porong lebih senang berkumpul bersama-sama memainkan game clash of clans. Siswa berkumpul dengan teman sebaya dan memiliki kegemaran sama yaitu bermain game clash of clans. Siswa senang memainkan game clash of clans bersama-sama karena merasa lebih ramai. Hal ini sejalan dengan teori motivasi (McClelland, 1976). Teori motivasi berafiliasi atau bersahabat yang mencerminkan hal tersebut adalah siswa akan mengikuti apa yang teman mereka lakukan salah satunya dengan ikut bermain game clash of clans. Bermain game clash of clans merupakan salah satu agar siswa tersebut dapat bersama-sama bermain dan diterima dalam pertemanannya.

Siswa SMPN 1 Porong bermain game clash of clans secara bersama-sama ketika mereka berada di sekolah dan berkumpul bersama di warung kopi. Sekolah maupun warung kopi menjadi tempat favorit siswa untuk bermain game clash of clans karena keberadaan free wifi. Sekolah memberikan free wifi karena digunakan untuk tujuan mempermudah siswa mengakses pembelajaran namun terkadang disalahgunakan untuk bermain game clash of clans ketika istirahat, jam kosong bahkan saat pembelajaran.

Kehadiran warung kopi dengan fasilitas free wifi membawa dampak bagi siswa SMP. Seluruh informan dalam penelitian ini mengaku pernah pergi ke warung kopi dengan maksud mencari internet akses. Siswa SMP yang seharusnya belajar ketika malam lebih memilih pergi ke warung kopi hanya untuk mencari free wifi. Akses internet yang ditawarkan oleh warung kopi yang berada di kecamatan Porong cukup stabil sehingga siswa merasa senang dengan keberadaan warung kopi dari pada belajar.

Selain pengaruh dari teman, siswa juga bermain game clash of clans karena merasa penasaran dengan game tersebut. Setelah memainkannya siswa menjadi senang dan kemudian memainkannya untuk menghilangkan kesepian, rasa bosan terhadap aktivitas sekolah dan kesedihan. Siswa bermain game clash of clans karena merasa kesepian, dia tidak memiliki kegiatan lain, ataupun tidak memiliki teman bermain. Siswa lebih senang menghilangkan kesepian itu dengan bermain game clash of clans.

Game clash of clans disenangi oleh siswa karena game ini menghadirkan update secara berkala. Kehadiran update secara berkala dapat menghilangkan rasa bosan pemain terhadap permainan tersebut. Selain update juga terdapat event yang mendorong siswa untuk bermain secara terus menerus. Salah satu event yang sering dihadirkan adalah diskon untuk pembuatan pasukan.

Game clash of clans merupakan game berbasis smartphone. Game berbasis smartphone lebih senang dimainkan oleh siswa karena game ini mudah dibawa kemana saja dan dapat dimainkan kapan saja. Game clash of clans dianggap lebih mobile dibandingkan dengan game online berbasis Personal computer (PC). Hal ini didukung oleh kemajuan teknologi dan mudahnya siswa memiliki smartphone dengan harga yang cukup terjangkau.

Pemain game clash of clans juga sering membuka tutorial melalui google dan youtube. Selain itu game clash of clans juga dapat dihubungkan dengan media sosial dalam hal ini facebook. Siswa tidak hanya bisa mengetahui cara bermain game clash of clans dari clan saja tetapi mereka juga memanfaatkan mulai dari browsing tutorial hingga sosial media. Sosial media juga digunakan oleh siswa untuk terhubung antar sesama anggota clan, siswa memanfaatkan berbagai macam sosial media mulai dari BBM, Line, dan Whatsaap. 
Berbagai kemudahan bagi siswa pemain game clash of clans menjadikan siswa lebih senang memainkan game ini. Hal ini diperkuat oleh Widarti (2010:7) mengatakan bahwa penyebab lain daya tarik game online adalah fitur yang menarik dari game online, banyaknya teknologi yang menyediakan, memudahkan pemain mengakses game online dan keberadaan kompetisi game online.

\subsection{Karakteristik Pemain Game Clash of Clans di SMPN 1 Porong}

Karakteristik pemain game clash of clans di SMPN 1 Porong dapat diketahui berdasarkan hasil penelitian yang telah dilakukan. Pemain game clash of clans di SMPN 1 Porong seluruhnya merupakan siswa laki-laki. Hal tersebut dikarenakan game bertema real-time strategi membutuhkan waktu yang lama dalam memainkannya. Hal ini didukung oleh pernyataan Silvandha (2012) bahwa tidak banyak perempuan yang betah berlama-lama menghadapi game yang sama dan memiliki alur yang tiada kata tamatnya.

Laki-laki memainkan game clash of clans karena menyukai sifat pencapaian nilai dan keberhasilan dalam misi, sedangkan perempuan bermain game hanya untuk membentuk hubungan (Yee, 2006). Pencapaian nilai dan keberhasilan dalam game clash of clans dapat dicapai apabila pemain telah bergabung ke dalam clan. Ketika pemain tersebut memenangkan perang antar clan (clan wars) mereka akan mendapat penghargaan berupa gold (emas) dan elixir (sejenis sumber daya) bahkan kenaikan jabatan menjadi co-leader (wakil pemimpin).

Pemain game clash of clans di SMPN 1 Porong menyatakan bahwa mereka mempunyai rasa bangga ketika mendapatkan kenaikan jabatan dalam clan. Pemain clash of clans menjadi lebih dihargai dan lebih mudah mengatur pemain lainnya karena mereka memiliki kuasa dalam clan. Hal tersebut didukung oleh (Bartle, 1996) bahwa pemain pria lebih memilih peran berprestasi dalam bermain game online.

Motivasi prestasi yang dimiliki oleh pemain game clash of clans bisa dikaitkan dengan teori motivasi (McClelland, 1976) yaitu motivasi untuk berprestasi dan motivasi untuk berkuasa. Motivasi berprestasi terjadi ketika pemain game clash of clans mendapatkan kenaikan jabatan. Jabatan yang didapatkan menyebabkan pemain memiliki rasa kepercayaan diri dan dihargai oleh pemain lainnya. Ketika pemain mendapatkan jabatan, mereka akan memiliki motivasi untuk menguasai clan. Kekuasaan yang mereka dapatkan menjadikan mereka memiliki tingkatan lebih dibandingkan dengan pemain lainnya, mereka memiliki kuasa untuk mengatur anggota lain dan mengatur strategi dalam clan.

Karakteristik pemain game clash of clans di SMPN 1 Porong selain laki-laki adalah mereka memiliki waktu luang untuk memainkan game. Umumnya game bertema real-time strategi seperti game clash of clans harus dimainkan secara terus menerus. Bermain secara terus menerus akan meningkatkan level pemain begitupun dengan level clan. Pemain game clash of clans di SMPN 1 Porong memiliki dan dapat menyisihkan waktu luang hanya untuk bermain game dibandingkan untuk belajar. Hal tersebut terbukti dengan adanya siswa yang memainkan game clash of clans di rumah bahkan di sekolah.

Pemain game clash of clans di SMPN 1 Porong menyatakan bahwa rata-rata mereka bermain selama 2-3 jam perhari. Bahkan beberapa siswa bermain game clash of clans lebih dari 6 jam perhari. Pemain game clash of clans juga selalu menambah durasi bermain mereka ketika libur sekolah dan tidak ada aktivitas yang harus dilakukan. Peningkatan waktu bermain 
merupakan salah satu indikator seorang kecanduan game. Hal ini didukung oleh pernyataan Young (1996) bahwa seorang yang kecanduan game merasakan kebutuhan waktu dalam bermain game online terus meningkat untuk mencapai sebuah kepuasan.

Karakteristik pemain game clash of clans selanjutnya adalah pemain merupakan siswa yang berasal dari keluarga berkecukupan. Syarat utama untuk dapat memainkan game clash of clans yaitu dia harus memiliki smartphone dan akses internet (kuota). Pemain game clash of clans mengeluarkan biaya secara rutin untuk membeli kuota internet. Biaya yang dikeluarkan siswa SMPN 1 Porong untuk bermain clash of clans (akses internet) rata-rata Rp. 20.000 perminggu. Siswa mendapatkan uang tersebut dengan cara menabung. Hasil tabungan tersebut kemudian dibelikan kuota internet. Bahkan ada salah satu siswa yang rela membantu pamannya berdagang agar mendapat tambahan uang saku.

\subsection{Dampak Game Clash of Clans Terhadap Hasil Belajar Siswa di SMPN 1 Porong}

Keberadaan smartphone di SMPN 1 Porong selain memudahkan orang tua dalam menghubungi anaknya juga dapat mengganggu siswa dalam proses pembelajaran. SMPN 1 Porong memberikan kebijakan untuk meminimalisir gangguan smartphone dalam pembelajaran dengan menyediakan loker khusus smartphone. Ketika proses pembelajaran, siswa harus meletakkan smartphone ke dalam loker.

Keberadaan loker khusus smartphone ternyata tidak sepenuhnya efektif. Hal ini dibuktikan masih banyaknya siswa yang tidak mentaati peraturan tersebut, sehingga masih bayak siswa yang memainakan smartphone saat proses pembelajaran. Biasanya siswa memainkan smartphone untuk bermain game, salah satu game yang sering dimainkan adalah clash of clans. Banyak siswa SMPN 1 Porong memainkan game clash of clans di sekolah sampai lupa waktu dan lupa belajar.

Aturan yang mengharuskan siswa meletakkan smartphone di dalam loker membuat siswa tidak dapat memainakan game clash of clans saat pembelajaran. Hal ini menyebabkan pemain game clash of clans merasa resah ketika tidak dapat bermain, mereka merasa khawatir dengan keadaan game mereka. Siswa yang merasa selalu kepikiran game ketika pembelajaran dikategorikan bahwa dia kecanduan game. Hal ini seperti yang diungkapkan oleh (Young, 1996) bahwa seorang yang kecanduan game akan merasa terikat dengan game dan selalu memikirkan mengenai aktivitas bermain game.

Khusus untuk pemain game clash of clans, mereka merasakan gangguan mulai dari ketakutan harta mereka dicuri musuh dan waktu yang dimiliki semakin sedikit untuk melindungi base dari serangan musuh. Game clash of clans yang mengedepankan strategi akan membuat siswa lebih menaruh konsentrasi mereka pada game dibanding dengan memperhatikan pelajaran. Siswa lebih menaruh perhatian kedalam game sehingga konsentrasi belajar menjadi terganggu. Hilangnya konsentrasi akan menyebabkan menurunnya hasil belajar siswa.

Hasil belajar yang baik dapat dicapai melalui proses belajar yang baik pula. Jika proses belajar tidak optimal sangat sulit diharapkan terjadinya hasil belajar yang baik. Proses untuk mendapatkan hasil belajar yang baik adalah dengan cara konsentrasi pada saat pembelajaran. Konsentrasi belajar siswa tidak hanya dibutuhkan ketika di sekolah namun juga di rumah. Siswa belajar di rumah seperti mengerjakan tugas maupun membaca buku pelajaran untuk 
persiapan esok hari. Siswa yang bermain game clash of clans terkadang melupakan tugas belajar mereka. Siswa lebih memilih bermain game clash of clans dari pada mengerjakan tugas.

Berdasarkan penelitian dapat diketahui bahwa terdapat dua tipe hasil belajar siswa yang kecanduan game clash of clans. Pertama, hasil belajar siswa yang kecanduan game clash of clans berada di bawah rata-rata (di bawah 80 ) dan diatas rata-rata (di atas 81). Siswa yang hasil belajarnya di bawah rata-rata disebabkan karena mereka tidak dapat mengendalikan diri dan mengatur waktu belajar. Siswa lebih senang memainkan game clash of clans dari pada belajar. Mereka tidak dapat membagi waktu untuk belajar dan bermain game. Hal ini dibuktikan dengan siswa yang bermain game clash of clans pada saat pembelajaran. Akibatnya mereka tidak fokus belajar dan konsentrasi belajar berkurang. Selain itu ketika ada tugas, mereka lebih mendahulukan game dan menyelesaikan tugas di sekolah dengan cara mencontek.

Lee dkk menyatakan anak yang sedang kecanduan game mengalami penurunan performa akademik karena cenderung menghabiskan banyak waktu di depan layar monitor komputer atau handphone untuk bermain sehingga membuat terkikisnya motivasi belajar dan prestasi menurun pada anak, serta membuat anak menjadi kurang berinteraksi pada lingkungan sekitar (Lee, I., Yu, C., \& Lin, H., 2007). Hal tersebut berkaitan dengan hasil belajar siswa SMPN 1 Porong yang tidak dapat mengatur waktu sehingga motivasi belajar mereka menurun. Akibatnya adalah hasil belajar yang menurun. Siswa lebih senang memainkan game dari pada belajar.

Kedua, siswa yang kecanduan game clash of clans tetapi hasil belajarnya di atas rata-rata. Dari hasil penelitian setidaknya ada tiga siswa yang memiliki nilai di atas rata-rata (lebih dari 81). Hal ini dikarenakan mereka dapat mengendalikan diri. Mereka memang kecanduan game clash of clans tetapi mereka masih bisa mengatur waktu kapan untuk belajar dan bermain. Mereka lebih memilih mengerjakan tugas dan belajar terlebih dahulu sebelum bermain game. Mereka juga tidak memainkan game clash of clans saat pembelajaran, meskipun terkadang mereka pernah kepikiran.

\section{Simpulan}

\subsection{Kesimpulan}

Latar belakang siswa SMPN 1 Porong bermain game clash of clans dipengaruhi oleh 3 macam yaitu pengaruh teman, kesepian dan fasilitas yang mendukung siswa bermain game clash of clans. Pengaruh teman dirasakan siswa menjadi dorongan terbesar mereka untuk bermain, karena mereka tertarik ketika melihat temannya bermain game clash of clans. kesepian juga siswa rasakan ketika sedang berada di rumah dan di sekolah, sehingga siswa mencari kesibukan lain dengan cara mencoba bermain game clash of clans. fasilitas yang mendukung juga menyebabkan siswa bermain game clash of clans. salah satu fasilitas yang tersediaD adalah free wifi di berbagai tempat termasuk sekolah dan warung kopi, update game secara berkala, serta game yang mudah dibawa kemana-mana.

Siswa pemain game clash of clans di SMPN 1 Porong memiliki karakteristik pertama, pemain adalah laki-laki. Kedua, pemain memiliki waktu luang sehingga mereka bisa memainkan game dan tidak memiliki kesibukan lain. Ketiga, pemain merupakan siswa yang berkecukupan karena pemain clash of clans membutuhkan smartphone dan biaya untuk koneksi internet. 
Hasil belajar siswa yang kecanduan game clash of clans di SMPN 1 Porong terdapat dua tipe. Pertama hasil belajar siswa rata-rata (80), hal ini diperoleh karena siswa yang tidak dapat mengendalikan diri dan mengatur waktu. Kedua, hasil belajar siswa di atas rata-rata (81), hal ini pada siswa yang dapat mengendalikan diri dan mengatur waktu untuk belajar.

\subsection{Saran}

Berdasarkan kesimpulan di atas, maka saran yang diajukan dirumuskan sebagai berikut. SMPN 1 Porong disarankan agar memperimbangkan kebijakan khususnya kebijakan mengenai diperbolehkannya siswa membawa smartphone, karena sering disalahgunakan oleh siswa. Perlu ketegasan pihak sekolah untuk melarang siswa bermain smartphone baik ketika pembelajaran maupun istirahat. Sekolah harus menyediakan loker dengan kunci untuk mengumpulkan smartphone siswa dan siswa diperbolehkan menggunakan ketika keadaan mendesak dengan didampingi guru piket. Pemblokiran dari pihak sekolah agar siswa tidak bisa mengakses situs-situs yang tidak ada hubungan dengan pembelajaran seperti situs game online. Bagi orang tua dapat mempertimbangkan ketika membelikan anaknya smartphone. Anak sering menggunakan smartphone untuk bermain game dari pada belajar. Pengawasan orang tua juga perlu ditingkatkan ketika anak memiliki smartphone. Anak harus memprioritaskan belajar dengan pengawasan orang tua ketika di rumah. Bagi peneliti selanjutnya untuk melakukan penelitian tentang peran serta sekolah dalam upaya mengatasi kecanduan game online khususnya game online berbasis smartphone dikalangan siswa. Dampak penggunaan smartphone di dunia pendidikan. Smartphone sering di salah gunakan ketika berada di dunia pendidikan misalnya memainkan game ketika pembelajaran.

\section{Daftar Rujukan}

Bartle. (1996). Hearts, clubs, diamonds, spades: players who suit MUDs. Journal of Virtual Environments, (Online). (http://mud.co.uk/richard/hcds.htm) diakses tanggal 2 Desember 2016.

Farida, A. (2014). Pilar-Pilar Pembangunan Karakter Remaja. Bandung: Nusa Cendekia.

Lee, I., Yu, C., \& Lin, H. (2007). Leaving a Never-Ending Game: Quitting MMORPGs and Online Gaming Addiction. Journal of Virtual Environments, (Online), (http://digra.org), diakses 3 Januari 2017.

Mappiare, A. (1982). Psikologi Remaja. Malang: Usaha Nasional.

McClelland, D. (1976). The Achievement Motive. New York: Irvington Publishers Inc.

Miles, M. B. \& Huberman, A. M. (1992). Analisis Data Kualitatif: Buku Sumber Tentang Metode-metode Baru. Jakarta: Universitas Indonesia Press.

Silvandha, A, dkk. (2012). Konsep Diri Pemain Game Online: Studi Fenomenologi tentang Konstruksi Konsep Diri Perempuan Pecanduan Online di Jakarta. Jurnal diterbitkan, (Online) 1 (1):1-16. (http://jurnal.unpad.ac.id), diakses 25 Oktober 2016.

Widarti, I. (2010). Hubungan antara Kontrol Diri dan Kecanduan Game Online pada Remaja di Malang. Malang: Universitas Negeri Malang.

Yee, N. (2006). The demographics, motivations and derived experiences of users of massively-multiuser online graphical environments. Presence: Teleoperators and Virtual Environments, 15, 309-329.

Young, K. S. (1996). Internet addiction: the emergence of a new clinical disorder. Cyberpsychology \& behavior, 1(3): 237-244. 